\title{
EXPERIMENTAL INVESTIGATION OF POWER TRANSFORMERS PROTECTION USING WAVELETS AND PATTERN RECOGNITION TECHNIQUES
}

\author{
A. S. Abd-Elatif \\ * Helwan University, Faculty of Engineering, \\ Dept. of Electrical Power \& Machines Engineering, Cairo, Egypt. \\ E-mail elptef2006@yahoo.com
}

\begin{abstract}
A few papers have been interested in the experimental investigation for the transformer protection; in this paper a real time laboratory investigation for power transformer protection is presented. A transformer of $(5 \mathrm{KVA}, 220 / 110 \mathrm{~V})$ is used to represent a power transformer. The current transducers are used to transfer the primary and secondary current signals of the tested transformer to the data acquisition system connected to pc by sampling frequency of $10 \mathrm{kHz}$. Lab- View package is used as software. The protection algorithm based on wavelet transform and pattern recognition (support vector machine) as described in [21]. The experimental results indicate that it are compatible with the simulated results and the proposed technique is stable, reliable, and fast during the discrimination between internal and external faults, magnetizing inrush currents, and switching on internal faults, so, the proposed technique can be used in the real time applications.
\end{abstract}

Keywords: Power transformer, wavelet transform, support vector machine, Lab-View and experimental setup. 


\section{INTRODUCTION}

Power transformer, as one of the most important apparatus in power system, it must be protected against the turn-to-turn faults. Although the various methods based on the terminal currents and/or voltages have been used for power transformer protection [1]. The differential protection has been the main protection on any power transformer. Unfortunately there are some challenges challenge the stability of the differential protection operation; such as unnecessary tripping occurs during switching with magnetizing inrush current in the primary windings of the transformer without loads at the secondary side, overexertion and the current transformer saturation during external faults. The solutions used to avoid these challenges can be divided to conventional and advanced techniques. The main conventional techniques based on using filters to analyze the differential current and extract the second harmonics and sometimes the fifth harmonics; these harmonics were used as the criteria to discriminate between magnetizing inrush currents and internal fault currents as they were found to have very high values in case of inrush currents and low values in case of fault currents [2], same solutions based on microprocessors and digital computers are used also [3-5]. There are huge numbers of researches based on advanced techniques are published to power transformer protection such as; Fuzzy logic in [6], where the proposed fuzzy logic-based relaying make use of flux-differential current derivative curve, harmonic restraints, and percentage differential characteristic curve for the purpose of overcoming limits of conventional relaying. Artificial Neural Networks (ANN) is used also in [7-8], However the accuracy of ANN depends on the number of the layers so the increasing of layer to make accurate relay has bad effect on the response time of it. Positive sequence admittance is applied in [9-10] without depending on harmonics but the used techniques have complicated calculations and hardware's. the instantaneous calculation of inductance is used in [11], these two techniques are sensitive to transformer capacity and the core type. The correlation factor is used to distinguish between internal and inrush current and also used to avoid the problem of current transformer saturation during external faults [12]. An algorithm based on the fault-related incremental currents is proposed to detect a low-level transformer turn-to-turn fault is proposed in [13]. The Wavelet transform are used in many researches because of its ability to analyze the signal in both the frequency and time domains [14-19].[20] used both the wavelet transform and support vector machine (SVM) to protect the transformer, a conventional differential scheme determines if the transformer is faulty or healthy, and SVM to determine whether it is an inrush or an internal fault current, this increases the response time of the relay as there are two stages involved. A modification is done to the this algorithm in [21] to increase its speed and accuracy, where, a quarter of the power cycle of the transformer differential current was used as an input to the wavelet filter and SVM directly without having passed on a differential scheme. Moreover, the algorithm 
presented in [21] is able to discriminate between different types of transient conditions on the power transformer, such as, load switching, inrush currents, internal and external faults rather than just discriminating between internal faults and inrush currents.

The experimental investigation for the transformer protection is presented in a few papers such as investigated in [11] and [22] by using Data Acquisition Card and Arduino respectively.

This paper introduces an experimental investigation for the algorithm which its theoretical algorithm had been described in [21] was validated in the laboratory using a $5 \mathrm{KVA}, 380 / 110 \mathrm{~V}$, star/star transformer in this paper. The prototype model is tested under various loading, unloading (magnetizing inrush current) and faulty conditions in order to study its performance. The experimental results prepay assure simulated results based on the wavelet transform and SVM

\section{USED TECHNIQUE}

The principle of operation of the proposed technique is explained in part 1[21], a brief review is given here as;

a. Firstly, measurement of the instantaneous values of the current signals at two terminals of the transformer to obtain the differential current.

This current is used to extract the features that the technique uses it.

b. Secondly, determine the features.

The discrete wavelet transform has been used. the discrete wavelet transform that analyzes the signal in different frequency bands with different resolution by decomposing the signal in to a coarse approximation and detail information as shown in the figure(1)

Where

L (n): low pass filter

$H(n)$ : high pass filter

Each of The second detail, the third detail and the fourth detail have been divided to four section and the energy of each section has been measured by equation (1)

$\mathrm{e}=\sum_{\mathrm{i}=1}^{\mathrm{f}}|\mathrm{s}(\mathrm{i})|^{2}$

The feature that has been used can be represented:

$$
\mathrm{X}=\left[\mathrm{e}_{2}^{1}, \mathrm{e}_{3}^{1}, \mathrm{e}_{4}^{1}, \mathrm{e}_{2}^{2}, \mathrm{e}_{3}^{2}, \mathrm{e}_{4}^{2}, \mathrm{e}_{2}^{3}, \mathrm{e}_{3}^{3}, \mathrm{e}_{4}^{3}, \mathrm{e}_{2}^{4}, \mathrm{e}_{3}^{4}, \mathrm{e}_{4}^{4}, i_{r m s}\right]
$$

Where f: number of samples in a specific section (s)

$e_{d}^{h}: e$ is the energy, $h$ determines the section number of the detail and $d$ is the detail number

$i_{r m s}:$ Root mean square of quarter cycle of current. 
The vector $X$ is the feature that has been used to differentiate between all the cases of the power transformer (normal, inrush current, external fault, internal fault).

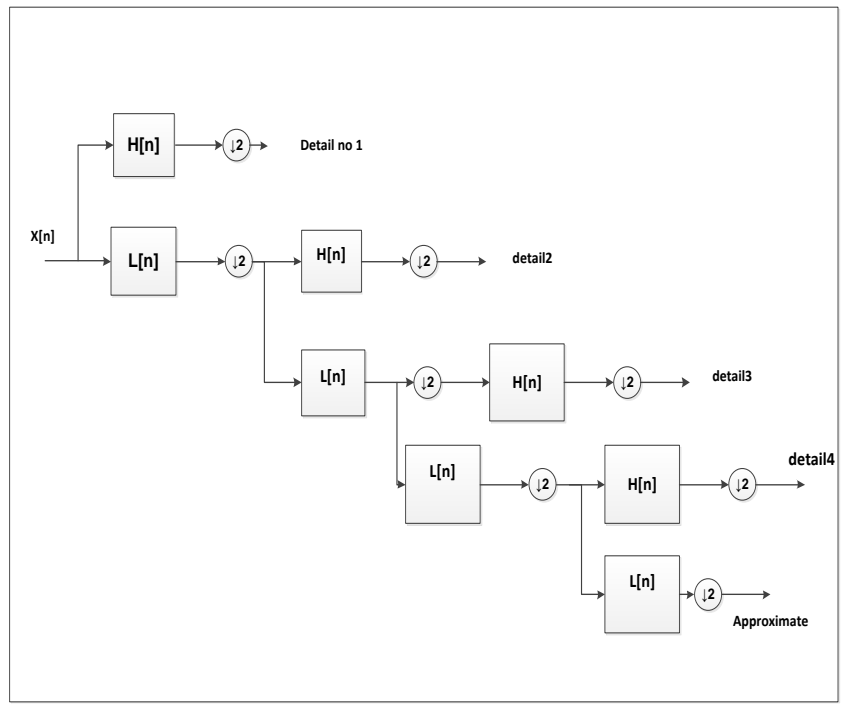

Figure (1) : the signal in approximation and detail coefficient

\section{c. Finally, Using of Support vector machine for discrimination.}

The support vector machine is used to draw a separate plane between two groups having different characteristics as shown in figure (2).

The hyperplane could be defined as:

$\sum_{\mathrm{i}=1}^{\mathrm{N}} \lambda_{\mathrm{j}}$ yi $\mathrm{K}\left(\mathrm{x}_{\mathrm{i}}, \mathrm{x}_{\mathrm{j}}\right)+\mathrm{W}_{0}=0$

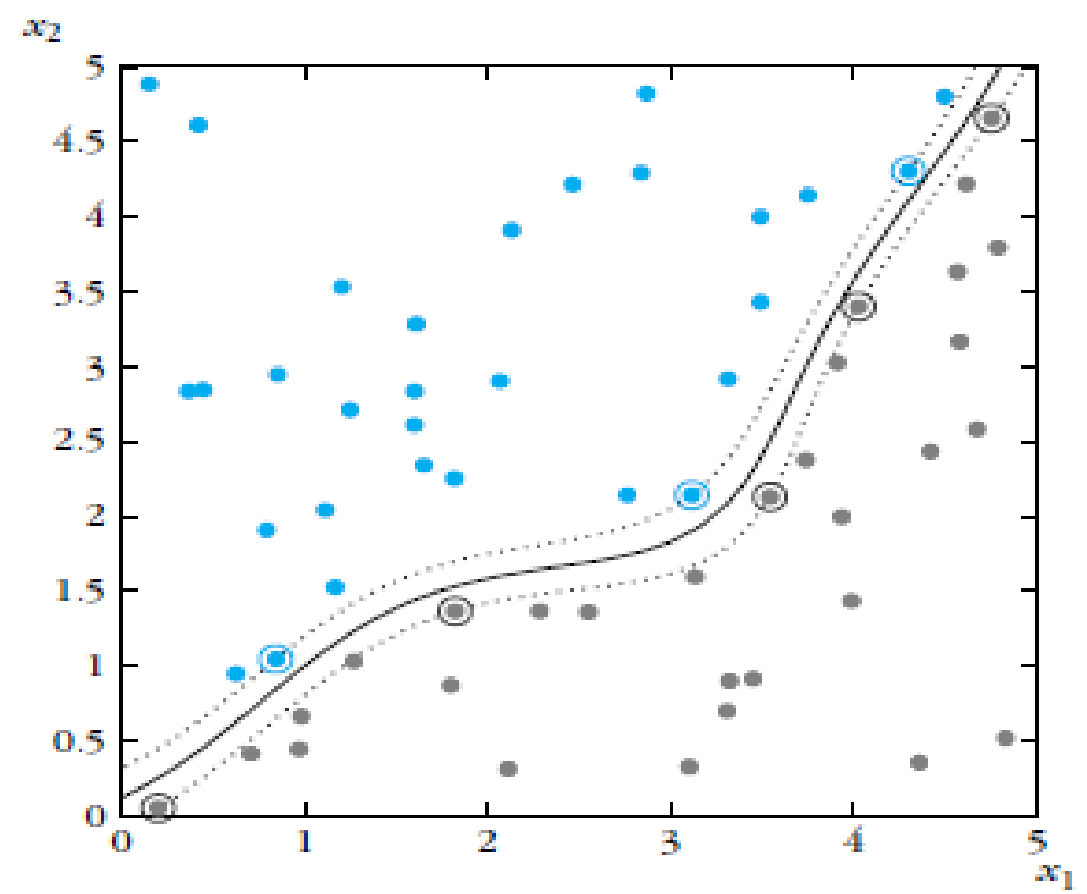

Figure (2): separate plane between two groups drawn by (SVM) 
Where:

$\lambda_{\mathrm{j}}$ : LaGrange multiplier determine as shown in part1

1yi : The classification output takes one or zero

$\mathrm{K}\left(\mathrm{x}_{\mathrm{i}}, \mathrm{x}_{\mathrm{j}}\right)$ : The kernel function determine as shown in part 1

$\mathrm{W}_{0}$ : Constant determine as shown in part 1

\section{EXPERIMENTAL SETUP}

Figure (3) shows the wiring diagram of the laboratory experimental setup, the components of the system are as follow,

- Tested three phase transformer (core type $5 \mathrm{KVA}, 380 / 190 \mathrm{~V}$ ), its parameters are given in table (1).

- The load (3 phase resistive load $3.6 \mathrm{kw})$,

- The actual current transducers (6 CT 30/5 turns ratio - $40 \mathrm{VA}$ )

- Electronic Protection Circuit to protect the input channels of the data acquisition card $( \pm 10 \mathrm{v})$, by using $20 \mathrm{~V}$ (peak to peak voltage) varistor.

- Data Acquisition Card with sample rate $10 \mathrm{~K} \mathrm{~Hz}$

The interface card receives six current signals from the primary and secondary sides of the tested transformer through six current transducers .The current signals are fed to the Data Acquisition Card interfaced with pc core i7 processor. Figure (4) shows the photograph of the overall experimental setup.

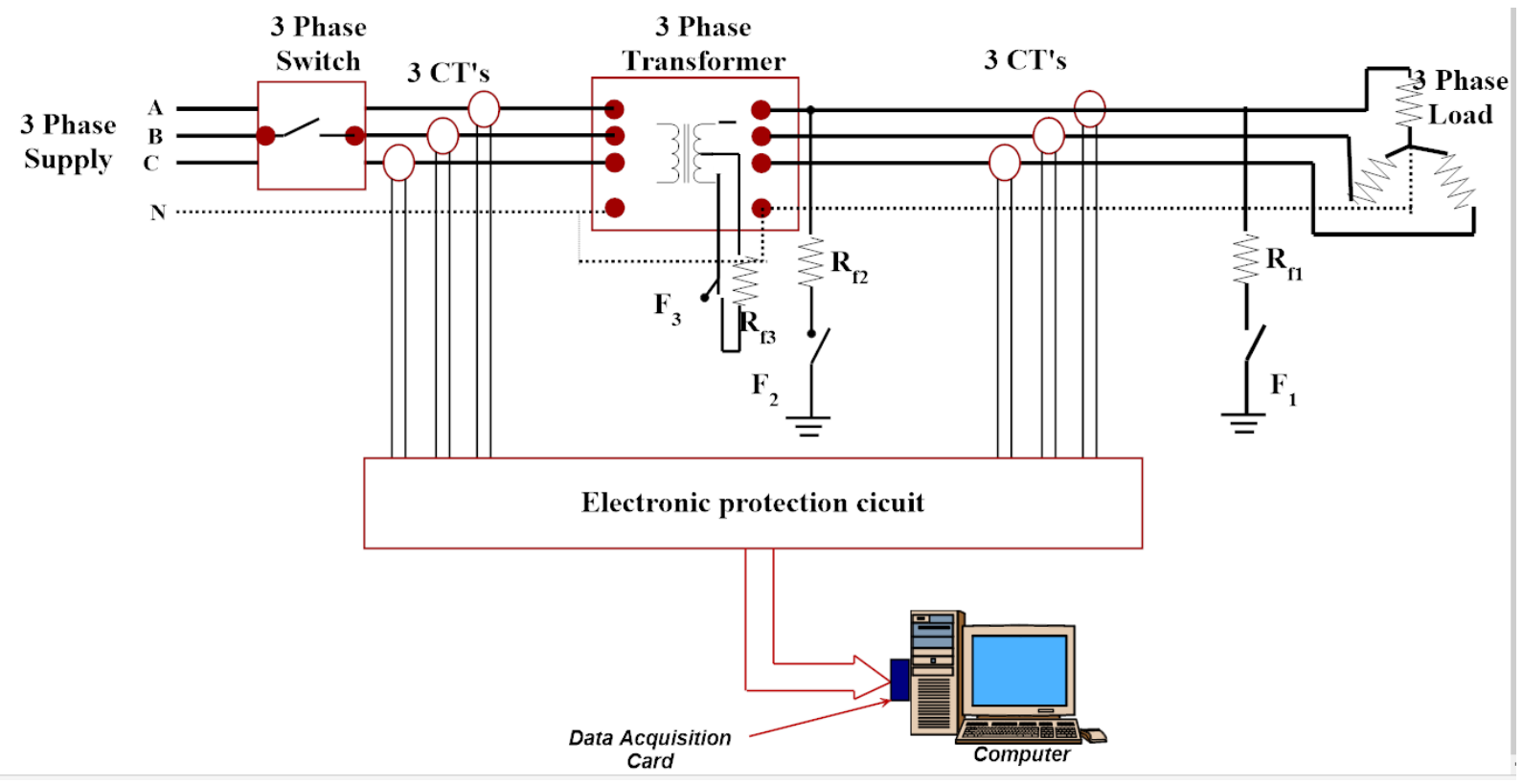

Figure (3): The wiring diagram of the laboratory experimental setup of the transformer 


\section{SOFTWARE IMPLEMENTATION}

Lab-View package is used to implement the proposed technique by using the real measurement as inputs to the program instead of simulated signals, the Lab-View is a powerful and flexible instrumentation it used to take measurements, control processes, and analyzing the stored data. Lab View uses a graphical programming language as the $\mathrm{G}$ graphical programming [23]. Simulation of the proposed technique by using Lab-View can be summarized as:

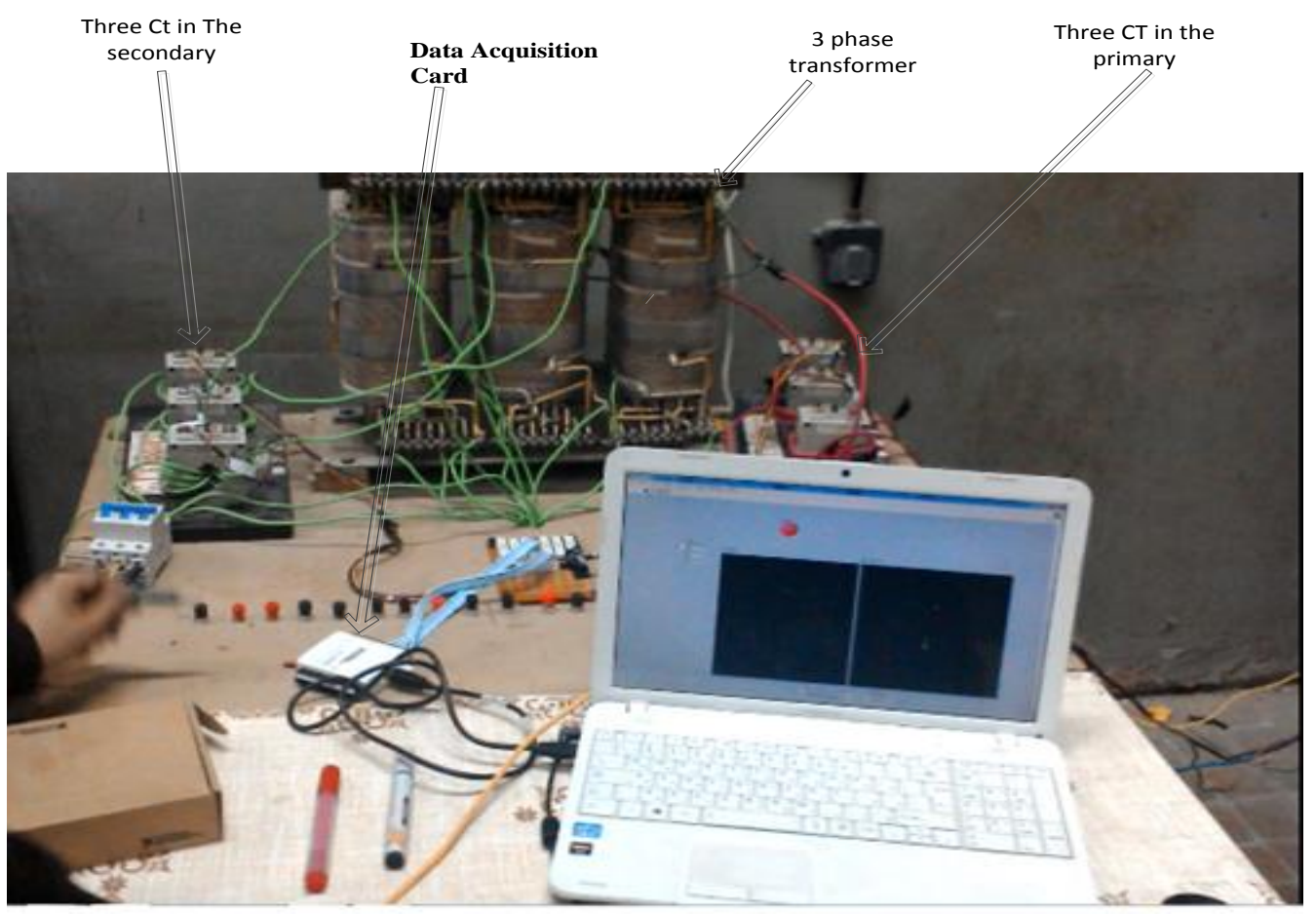

Figure (4): The photograph of the overall experimental setup.

Table 1: The transformer parameters

\begin{tabular}{||c|c|}
\hline Nominal power(base) and frequency. $\mathrm{V}_{\text {base }}(\mathrm{v})$ & $5(\mathrm{kVA}), 50(\mathrm{~Hz}) 220 \mathrm{~V}$ \\
\hline Winding 1 parameters $\left(\mathrm{V}_{1 \text { phase rms }}(\mathrm{V}), \mathrm{R}_{1}(\mathrm{pu}), \mathrm{L}_{1}(\mathrm{pu})\right.$ & $220(\mathrm{~V}), 0.001(\mathrm{pu}), 0.0000057(\mathrm{pu})$ \\
\hline Winding 2 parameters $\left(\mathrm{V}_{\text {2phase rms }}(\mathrm{V}), \mathrm{R}_{2}(\mathrm{pu}), \mathrm{L}_{2}(\mathrm{pu})\right)$ & $110(\mathrm{~V}), 0.001(\mathrm{pu}), 0.0000057(\mathrm{pu})$ \\
\hline Magnetization resistance an reactance $\left(\mathrm{R}_{\mathrm{m}}(\mathrm{pu}), \mathrm{L}_{\mathrm{m}}(\mathrm{pu})\right)$ & $0.3(\mathrm{pu}), .02(\mathrm{pu})$ \\
\hline
\end{tabular}

\section{a. Wavelet implementation}

Advanced signal processing toolkit in Lab VIEW has been used to extract the harmonic contents (wavelet details) as shown in the figure (5) 


\section{b. Measuring the energy}

Measuring the energy of each detail after dividing the detail into four sections as shown in the figure (6).

\section{a. Kernel function}

Obtain the kernel function as an input to the support vector machine as shown in figure (7). Asdescribed in [21] , the RBF Kernel function was chosen for this work.

\section{EXPERIMENTAL RESULTS}

As shown in figure (3) according to the lab possibilities the feeding of the transformer is done from one end only. Huge number of operation conditions under normal and fault cases are tested in real time to. The faults have been made through fault resistance 0-8 ohm.

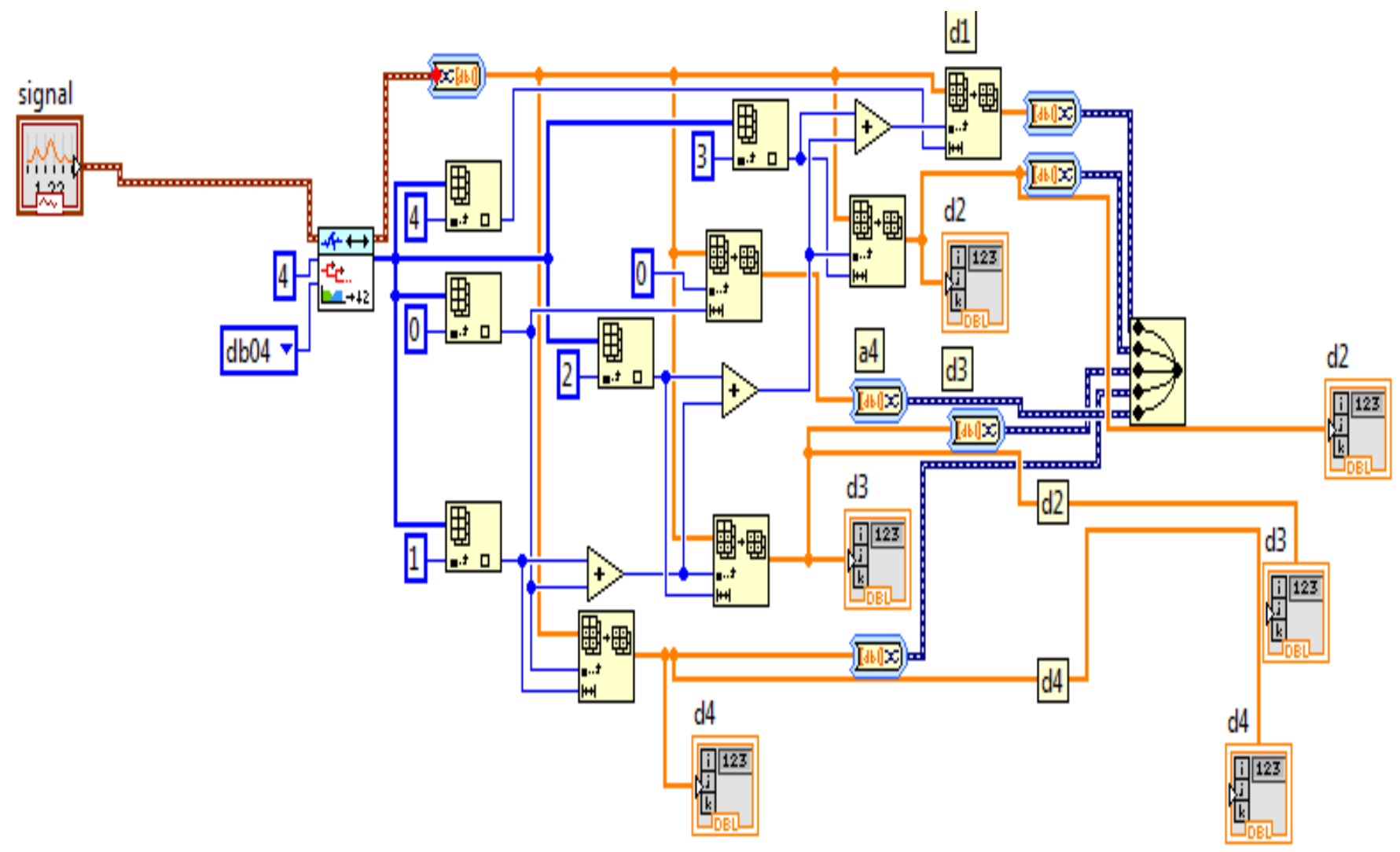

Figure (5): wavelet transforms and detail co-efficient 


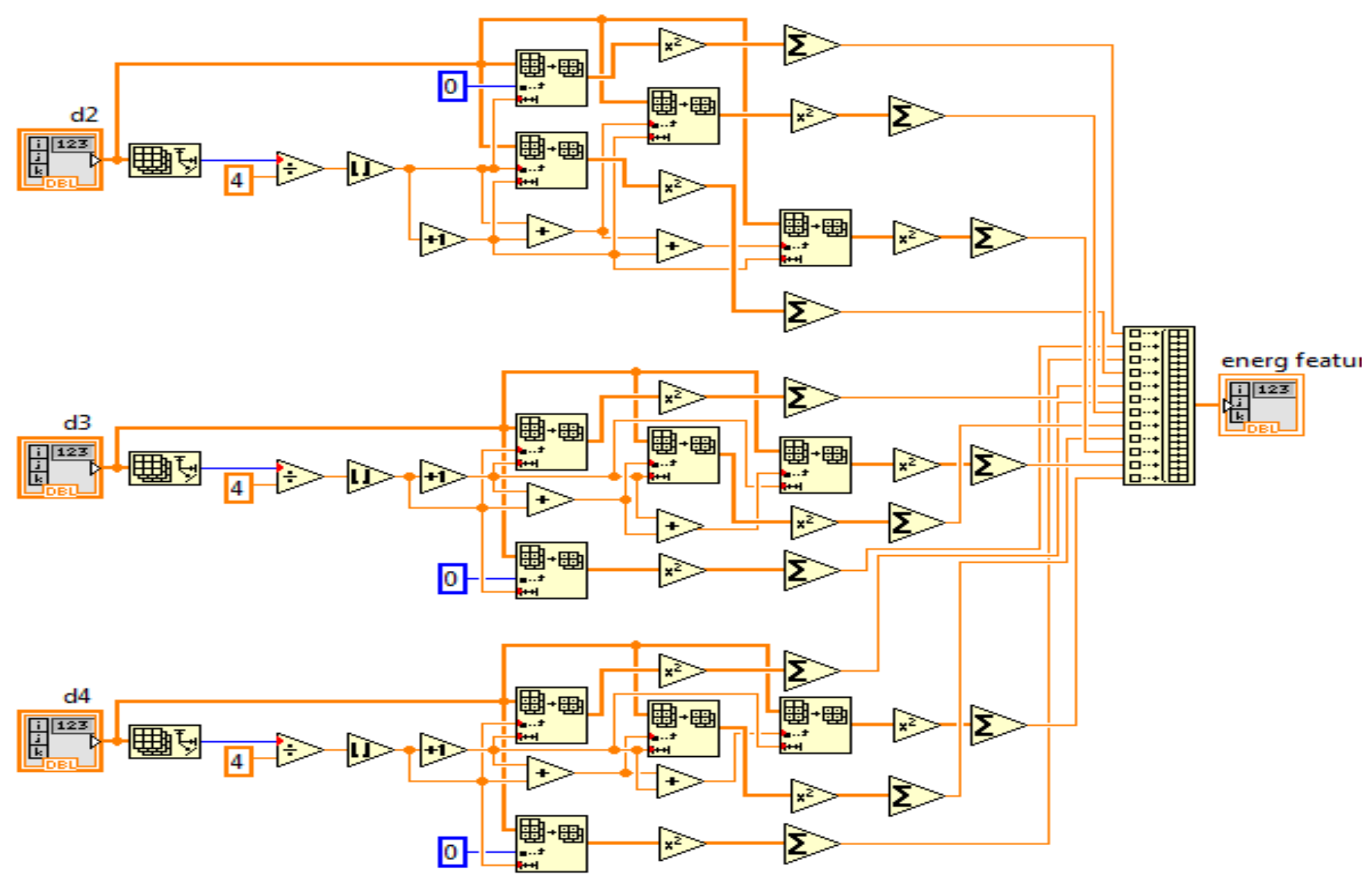

Figure (6): The energy calculation steps

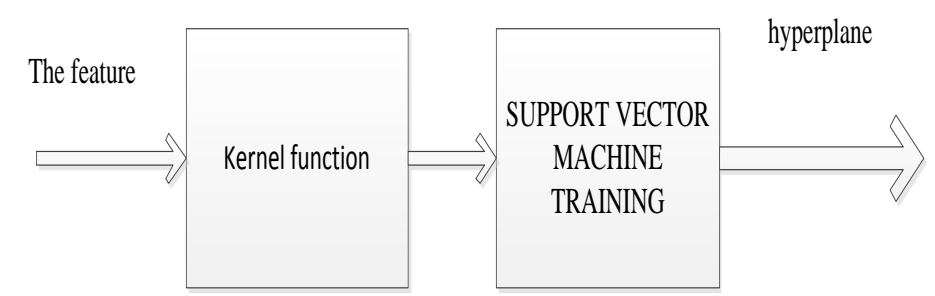

Figure (7): KERNEL function as an input to support vector machine

\section{a. The Relay Performance during External Fault}

As shown in figure (2). The external fault is done in the lab by closing switch $\left(\mathrm{F}_{1}\right)$ during normal operation. The primary and secondary current signals are shown in Figure (8) in case of SLG external fault at $F_{1}$, through fault resistance of $4 \Omega$. As shown in the figure the primary and secondary current are increased in the instant of closing switch $\left(\mathrm{F}_{1}\right)$. When these signals input to the PC by using data Acquisition system the output of the proposed technique which it simulated by Lab VIEW is zero. This indicates that the relay is able to discriminate such fault successfully as external fault. 


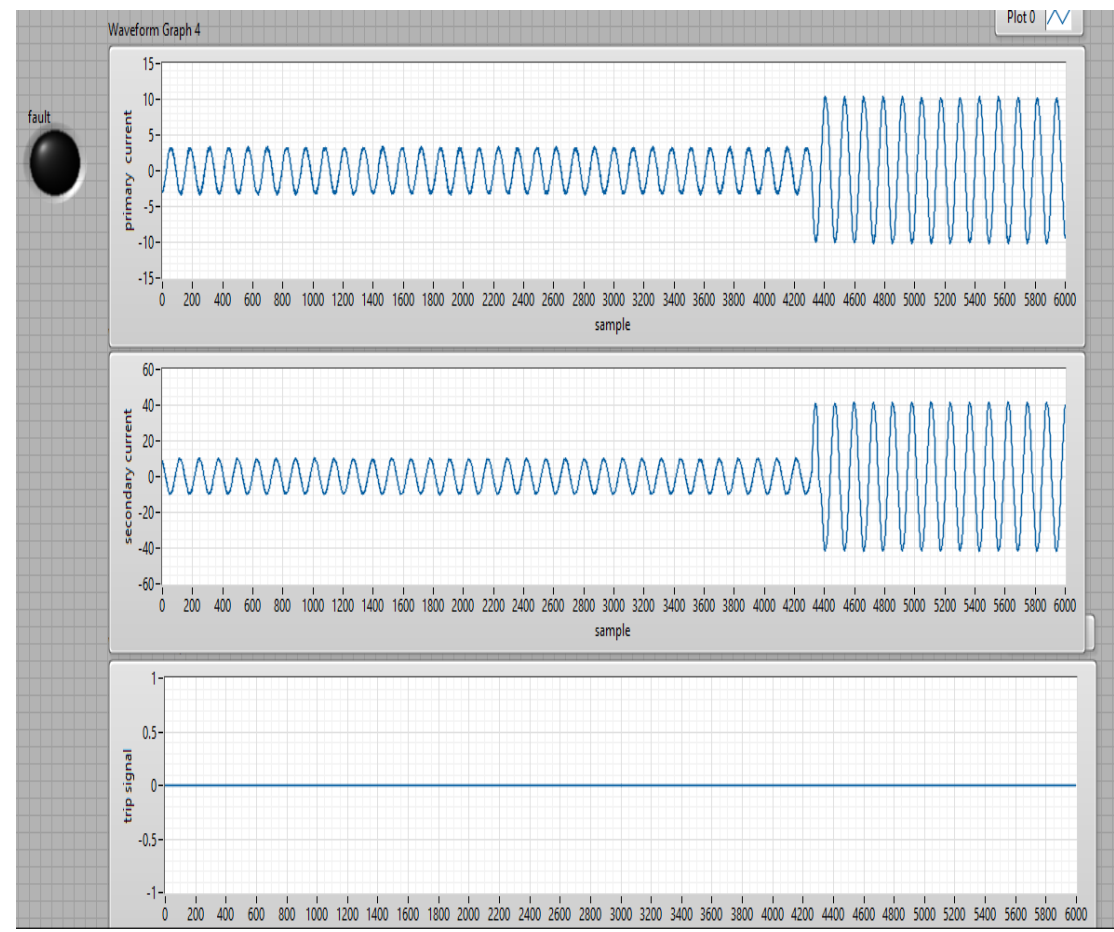

Figure (8): The relay response in case of SLG external fault

\section{a. The Relay Performance during Internal Fault at the secondary bushings}

The SLG internal fault through resistance with $8 \Omega$ at the secondary bushings of the tested transformer is represented by closing switch $\left(\mathrm{F}_{2}\right)$ between phase A and earth as shown in figure (2). The front panel of LabView is shown in figure (9); the differential current between primary and secondary sides is shown in the figure with high value by testing and training the data by the proposed algorithm the trip signal is activated at the instant of fault. This indicates that the relay is able to discriminate such fault successfully as internal fault.

\section{b. The Relay Performance during turn to turn fault at $\mathbf{4 0 \%}$ of the secondary side}

The switch $\left(\mathrm{F}_{3}\right)$ shown in figure (2) is used to represent the turn to turn fault at the secondary windings of the tested transformer at $40 \%$ of the windings. Figure (10) shows the front panel of Lab-View indicating that the testing and training data and the differential current for turn to turn fault by closing $F_{3}$ with resistance of $5 \Omega$. The trip signal is activated at the instant of fault. This indicates that the relay is able to discriminate such fault successfully as internal fault.

\section{c. The Relay Performance during Inrush Current}

The relay performance during switching cases and the inrush current are the main challenge for any transformer protection. The three phase supply switch is used for switching-on the transformer randomly many times to represent in the lab, while the secondary circuit and the fault switches are left opened. Figure (11 (a, b)) shows the front panel of the Lab-View indicating that the testing and training data for two different cases of switching on process and also shows the differential current. The trip signal is deactivated while this is healthy case. 


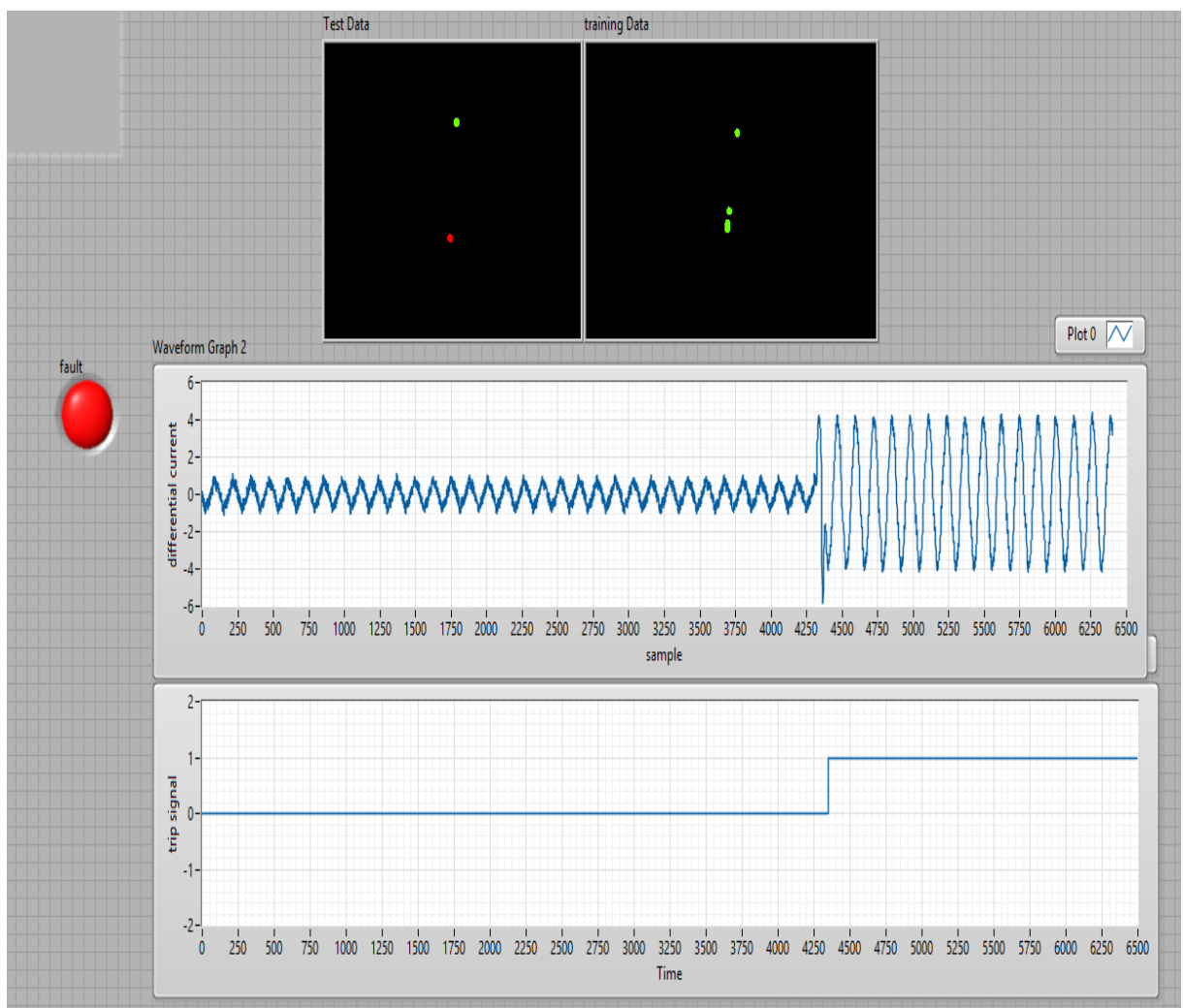

Figure (9): The relay response in case of SLG internal fault at the secondary bushings

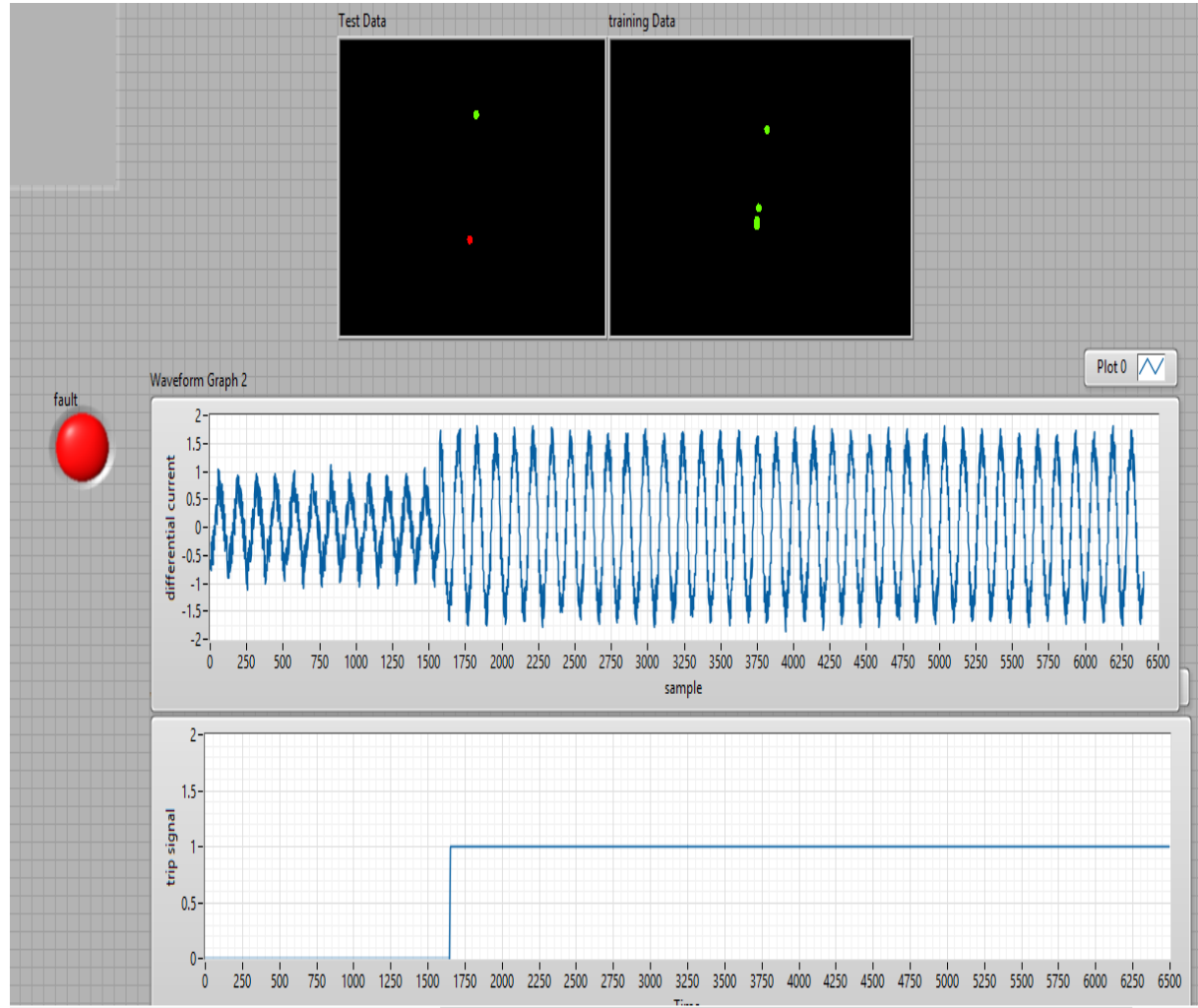

Figure (10): The relay response in case of SLG internal turn to turn fault 
A. S. Abd-Elatif / Engineering Research Journal 165(March 2020) E1-E13

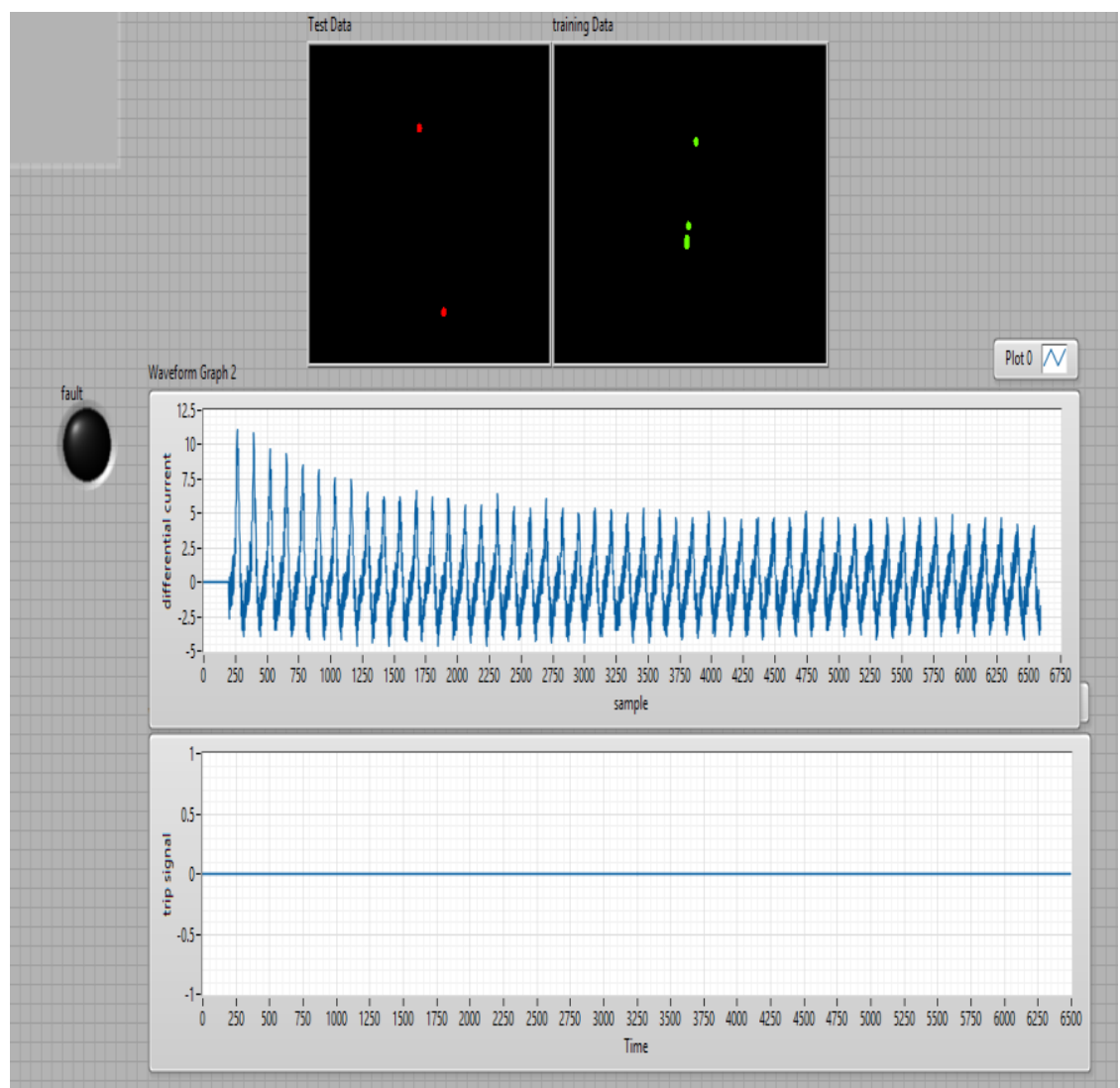

(a)

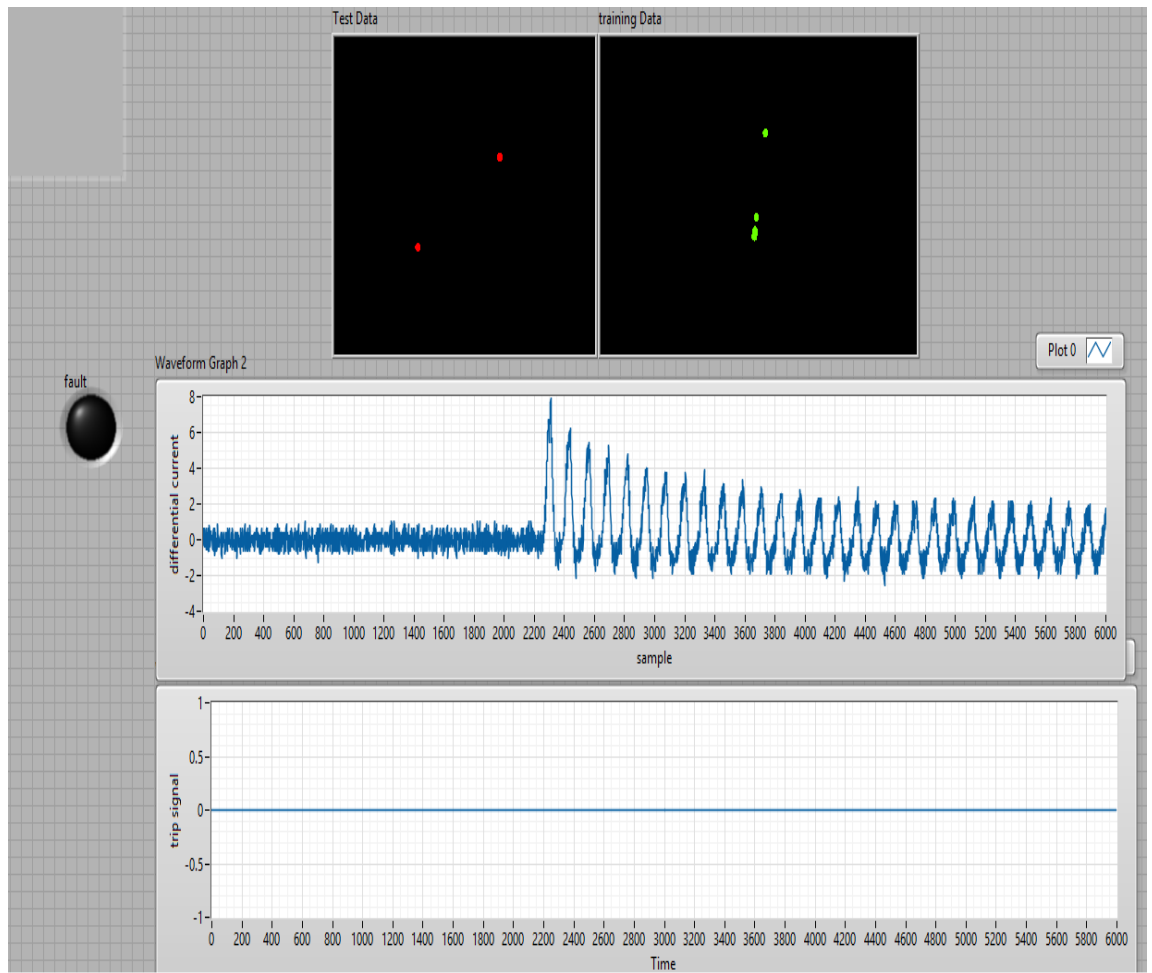

(b)

Figure (11): The relay response in case of inrush current
a) inrush current (Case 1)
b) inrush current Case 2 


\section{CONCLUSIONS}

The above study concluded that the reliable and secure performance of the proposed algorithm presented in the theoretical part and shown that it can be widely used in the actual advanced numerical relays. The prototype model is investigated and tested under various loading, inrush current and faulty conditions for internally and externally faults to study performance of the proposed algorithm in case of practical implementation. The experimental results indicate that they are compatible with the simulated results, the proposed technique based on the wavelet transform and SVM is stable, reliable, and fast during the discrimination between internal and external faults, magnetizing inrush currents, and switching on internal faults, so, the proposed technique can be used in the real time applications.

\section{References:}

[1] Farhad Haghjoo; Mohsen Mostafaei ; Hasan Mohammadi “A New Leakage Flux-Based Technique for Turn-to-Turn Fault Protection and Faulty Region Identification in Transformers" IEEE Transactions on Power Delivery ( Volume: 33 , Issue: 2 , April 2018 ).

[2] [M. A. Rahman and B. Jeyasurya, "A state-of-the-art review of transformer protection algorithms," Power Delivery, IEEE Transactions on, vol. 3, pp. 534-544, 1988.

[3] J. A. Sykes and I. F. Morrison, "A proposed method of harmonic restraint differential protection of transformers by digital computer" IEEE Trans. Power Apparat. Syst., vol. PAS-91, pp. 1266-1272, May/June 1972.

[4] M. E. Masoud, S.M.W. Ahmed "A microprocessor- based transformer percentage differential protection, part-I, Novel Technique in Transformer Protection" thirteen international congress for static, computer, science, social and demographic, 26 march-31 march, Cairo-Egypt.

[5] M. E. Masoud, S.M.W. Ahmed "A microprocessor- based transformer percentage differential protection, part II, Software and Test Result" thirteen international congress for static, computer, science, social and demographic, 26 march-31 march Cairo-Egypt.

[6] M. C. Shin, C. W. Park, and J. H. Kim "Fuzzy Logic-Based Relaying for Large Power Transformer Protection" IEEE Transactions on Power Delivery, Vol. 18, NO. 3, pp. 18-24 JULY 2003.

[7] N K Patel, R K Khubchandani, "ANN Based Power Transformer Fault Diagnosis" Journal EL, Vol 85, pp. 60-63June 2004 IE (I).

[8] "Classification and Discrimination Among Winding Mechanical Defects, Internal and External Electrical Faults, and Inrush Current of Transformer" PP(99):1-1 · June 2017

[9]

[10] M. Eissa, E. Shehab-Eldin, M. Masoud, and A. Abd-Elatif, "Digital technique for power transformer fault detection based on positive sequence admittance approach," in Power System Conference, 2008. MEPCON 2008. 12th International Middle-East, 2008, pp. 517-522.

[11] M. Eissa, E. Shehab-Eldin, M. Masoud, and A.Abd-Elatif, "Experimental Investigation for Digital Power Transformer Fault Detection Based on positive Sequence Admitt ance Approach " in Power System Conference, 2009. MEPCON 2009. 13th International Middle-East, 2009, pp. 273-279.

[12] G. Baoming, A. T. De Almeida, Z. Qionglin, and W. Xiangheng, "An equivalent instantaneous inductance-based technique for discrimination between inrush current and internal faults in power transformers," Power Delivery, IEEE Transactions on, vol. 20, pp. 2473-2482, 2005.

[13] Nima Farzin ; Mehdi Vakilian ; Ehsan Hajipour "Transformer Turn-to-Turn Fault Protection Based on Fault-Related Incremental Currents" IEEE Transactions on Power Delivery ( Volume: 34 , Issue: 2 , April 2019 ) Page(s): 700 - 709 


\section{A. S. Abd-Elatif / Engineering Research Journal 165(March 2020) E1-E13}

[14] P. L. Mao and R. K. Aggarwal, "A novel approach to the classification of the transient phenomena in power transformers using combined wavelet transform and neural network," Power Delivery, IEEE Transactions on, vol. 16, pp. 654-660, 2001.

[15] H. Zhang, J. Wen, P. Liu, and O. Malik, "Discrimination between fault and magnetizing inrush current in transformers using short-time correlation transform," International journal of electrical power \& energy systems, vol. 24, pp. 557-562, 2002.

[16] A.-R. Sedighi and M.-R. Haghifam, "Detection of inrush current in distribution transformer using wavelet transform," International Journal of Electrical Power \& Energy Systems, vol. 27, pp. 361-370, 2005.

[17] Rodrigo Prado Medeiros ; Flavio Bezerra Costa "A Wavelet-Based Transformer Differential Protection: Internal Fault Detection During Inrush Conditions" IEEE Transactions on Power Delivery ( Volume: 33 , Issue: 6 , Dec. 2018 ) Page(s): 2965 - 2977

[18] Yujia Deng ; Sheng Lin ; Ling Fu ; Kai Liao ; Lei Liu ; Zhengyou He ; Shan Gao ; Yilu Liu "New Criterion of Converter Transformer Differential Protection Based on Wavelet Energy Entropy' IEEE Transactions on Power Delivery ( Volume: 34 , Issue: 3 , June 2019 ) Page(s): 980 - 990

[19] Arpita Roy ; Devender Singh ; Rakesh Kumar Misra ; Amit Singh "Differential protection scheme for power transformers using matched wavelets" IET Generation, Transmission \& Distribution ( Volume: 13 , Issue: 12,6182019 )

[20] S. Jazebi, B. Vahidi, and M. Jannati, "A novel application of wavelet based SVM to transient phenomena identification of power transformers," Energy Conversion and Management, vol. 52, pp. 1354-1363, 2011.

[21] A. S. Ahmed ; A. M. Mohamed; S. M. Mohamed "Power transformer protection using wavelets and pattern recognition — part I: Theoretical verification" 2017 Nineteenth International Middle East Power Systems Conference (MEPCON17), pp:229 - 234.

[22] Sarfaraz Nawaz Syed S. Radhika M.N. Sandhya Rani "Differential Current Protection of Transformer using Arduino with Voice Alert" International Journal of Innovations in Engineering and Technology (IJIET), Volume6Issue2December2015.

[23] R. H. Bishop" Learning with Lab-View" Book, Addison Wasley Longman, Inc. 1999. 